\title{
ANTIBIOGRAM AND MOLECULAR CHARACTERIZATION OF VIBRIO CHOLERAE ISOLATED FROM MARINE FISH
}

\author{
RWARINDA U ANGELO, SAMIRAJ RAMESH*
}

Department of Microbiology, PRIST University, Thanjavur - 614 904, Tamil Nadu, India. Email: marineramesh2020@gmail.com

Received: 16 February 2017, Revised and Accepted: 11 March 2017

ABSTRACT

Objective: Molecular identification and antibiotic susceptibility evaluation of Vibrio cholerae from marine fish available in local fish market Thanjavur, Tamil Nadu, India.

Methods: Inoculation was done using nutrient agar as general media and thiosulfate-citrate-bile salts-sucrose agar as selective media and confirmed as $V$. cholerae by Gram-stain (microscopic observation), growth characteristics of different media, biochemical tests such as methyl red test, nitrate reduction tests, and indole test. Sensitivity (drug sensitivity) was done in Mueller-Hinton agar using disc diffusion method 10 different antibiotics were used to evaluate the antibiogram profile, molecular detection was done by targeting 16S rRNA gene using a universal primer.

Results: V. cholerae is present in marine fish samples, as showed by culture method and microscopic observation as well biochemical tests. Polymerase chain reaction (PCR) amplification of $16 \mathrm{~S}$ rRNA gene showed the amplification of targeted gene and antibiogram profile showed that isolates are more sensitive to ampicillin in comparison with others antibiotics used in this study. Ampicillin can be used for $V$. cholerae infection by the physicians and amoxicillin must be avoided which is resistant.

Conclusion: Molecular detection is safe and rapid methods for bacteria identification as revealed by PCR amplification of $16 \mathrm{~S}$ rRNA gene. As the isolates are more sensitive to ampicillin in comparison with others antibiotics used in this study. Ampicillin can be used for $V$. cholerae infection by the physicians and amoxicillin, and nitrofurantoin must be avoided.

Keywords: Bacteria, Vibrio cholerae, Molecular identification, Universal primer, 16S rRNA gene.

(C) 2017 The Authors. Published by Innovare Academic Sciences Pvt Ltd. This is an open access article under the CC BY license (http://creativecommons. org/licenses/by/4. 0/) DOI: http://dx.doi.org/10.22159/ajpcr.2017.v10i6.17883

\section{INTRODUCTION}

Cholera continues to be a serious public health problem in developing countries [1] where the disease is endemic, and several outbreaks have been reported. Historical records suggest that cholera-like disease may have been first reported in the Era of Hippocrates (460-377 BC). The geographical distribution of cholera is changing and so is often considered as a re-emerging disease, in part because infections are appearing in novel communities or in communities where the disease had been absent for many years. This may be due to the changes in the environment or climate, following the EL Nino phenomenon which has made conditions favorable for cholera worldwide [2]. The problem of global warming and the inland incursion of sea water covering more and more of the coastal stretches of land could lead us to the brink of a resurgent pandemic. Worldwide there has been increasing in the number of cholera cases and outbreaks in the new communities and with changing profile [3]. During the $19^{\text {th }}$ century, cholera spread across the world from its original reservoir in the Ganges delta in India [4]. The seventh pandemic started in South Asia in 1961 and reached Africa in 1971 and the Americas in 1991. Vibrio cholerae 01 El Tor biotype was the causative agent of the seventh pandemic. In 1992, V. cholerae 0139 was isolated in India and then in Bangladesh. It was the first non-01 serotype responsible for cholera epidemics. El Tor $V$. cholerae has replaced their classic counterpart over the past few decades [3]. Cholera outbreaks occur seasonally and are associated with monsoon season, warm temperature, heavy rainfall, and increased plankton population. $V$. cholerae has a unique ability to exist in an autochthonous state in the river and brackish water estuaries and coastal waters and can exist in dwarfish forms in response to nutrient deprivation as a viable but non-culturable form. It can exist in the gut and attached to the surface of both freshwater and marine copepods. In addition, the genetic assortments and re-assortments that are going on in these isolates, equip them appropriately to survive better in the changing environmental conditions [5,6]. In the year 2014, a total of 190-549 cases of cholera were reported from 42 countries with a case fatality rate of $1.17 \%$. This study was conducted with the aim of characterizing molecular and evaluating the antibiotic profile of $V$. cholerae isolated from marine fish.

\section{METHODS}

\section{Sample collection and isolation}

Marine fish samples were collected from the local fish market in Thanjavur, Tamil Nadu. Four different species marine fishes were collected including Sardinella longiceps, Rastrelliger kanagurta, Epinephelus tauvina, and Scomberomorus guttatus. To examine the bacterial organisms in the fishes taken for study, the methods of culture and plating as described by Venkataraman and Sreenivasan (1952) were followed. The tissues of S. longiceps, R. kanagurta, E. tauvina, and S. guttatus were dissected and processed. The $25 \mathrm{~g}$ portions were cut, homogenized with $225 \mathrm{ml}$ peptone saline water and after serial dilution, they were subjected to the separate culture medium.

\section{Media}

Culture technique procedures recommended by Bergey (1948) were followed. The media employed for the isolation of $V$. cholerae were nutrient agar, nutrient broth, Mac Conkey agar, and thiosulfate-citratebile salts-sucrose (TCBS) agar (Hi-Media, India) and these were time tested ones in bacterial cultures.

\section{Biochemical characterization}

The isolated pathogens were subjected to biochemical tests for further confirmation apart from the culturing methods. The following are the 
tests performed during this study oxidase, catalase, indole, methyl red, Vp citrate, triple sugar iron (TSI), urease, and nitrate reduction were carried out following the standard process in the biochemical analysis.

\section{DNA isolation}

DNA from the bacterial genome was extracted as per standard proteinase-K digestion method. Bacterial cultures were prepared and suspended in Luria-Bertani broth (Hi-Media, India) and incubated at $37^{\circ} \mathrm{C}, 110 \mathrm{rpm}$ for $12 \mathrm{hrs}$. The 12 -hr old bacterial cells were pelleted at $15,000 \times g$ or 10 minutes and then suspended in Tris- $\mathrm{HCl}(\mathrm{pH} 7.2)$, $10 \mathrm{mM}$ ethylenediaminetetraacetic acid (EDTA), $250 \mathrm{mM} \mathrm{NaCl}$ buffer having $1 \%$ sodium dodecyl sulfate (Hi-Media, India). Proteinase-K (HiMedia, India) was then added to a final concentration of $100 \mu \mathrm{g} / \mathrm{ml}$ and mixed gently. The suspension was incubated at $37^{\circ} \mathrm{C}$ for 60 minutes. DNA obtained by sequential phenol-chloroform and chloroformisoamyl alcohol extractions was precipitated by adding 2.5 volumes of absolute ethanol, and DNA was suspended in $100 \mu \mathrm{l}$ of TE buffer (10 mM Tris-HCl, 1 mM EDTA-pH 7.5). DNA was checked for purity by agarose gel electrophoresis.

Polymerase chain reaction (PCR) amplification of $16 S$ rRNA gene PCR reaction was performed in a gradient thermal cycler (Eppendorf, Germany). The universal primers (Forward primer 5'-AGAGTTTGATCMTGGCTCAG-3' and reverse primer 5 '-GGTTACCTTGTTACGACTT-3') were used for the amplification of the 16S rRNA gene fragment. The reaction mixture of $50 \mu \mathrm{l}$ consisted of $10 \mathrm{ng}$ of genomic DNA, $2.5 \mathrm{U}$ of Taq DNA polymerase, $5 \mu \mathrm{l}$ of $\times 10$ PCR amplification buffer (100 mM Tris- $\mathrm{HCl}, 500 \mathrm{mMKCl} \mathrm{pH}-8.3)$, $200 \mu \mathrm{M}$ deoxynucleotide triphosphate, $10 \mathrm{p}$ moles each of the two universal primers and $1.5 \mathrm{mM} \mathrm{MgCl}_{2}$. Amplification was done by initial denaturation at $94^{\circ} \mathrm{C}$ for 3 minutes, followed by 30 cycles of denaturation at $94^{\circ} \mathrm{C}$ for 30 seconds, the annealing temperature of primers was $55^{\circ} \mathrm{C}$ for 30 second and extension at $72^{\circ} \mathrm{C}$ for 1 minute.

The final extension was conducted at $72^{\circ} \mathrm{C}$ for 10 minutes. Agarose gel electrophoresis of PCR product was carried out as follow $10 \mu \mathrm{l}$ of the reaction mixture was then analyzed by submarine gel electrophoresis using $1.0 \%$ agarose with ethidium bromide at $8 \mathrm{~V} / \mathrm{cm}$ and the reaction product was visualized under gel documentation system.

\section{Antibiotic sensitivity tests}

Antibiotic sensitivity tests were carried on Mueller-Hinton agar (MHA) (Hi-Media, India) plates by Kirby-Bauer disk diffusion method (Bauer et al., 1966) [7] using antibiotic discs (Himedia, Mumbai, India) penicillin G (10 units), streptomycin $(10 \mu \mathrm{g})$, chloramphenicol $(30 \mu \mathrm{g})$, ampicillin $(10 \mu \mathrm{g})$, amoxicillin $(30 \mu \mathrm{g})$, tetracycline $(30 \mu \mathrm{g})$, ciprofloxacin $(5 \mu \mathrm{g})$, co-trimoxazole $(25 \mu \mathrm{g})$, nitrofurantoin $(10 \mu \mathrm{g})$, and norfloxacin $(10 \mu \mathrm{g})$ (Hi-Media, India). Characterization of the strains as susceptible, intermediately resistant, or resistant was based on the size of inhibition zones around each disc as per the manufacturer's instructions, which matched the interpretive criteria as per CLSI guidelines (CLSI, 2007).

\section{RESULTS}

In this study, four different fish species were used (S. longiceps, $R$. kanagurta, E. tauvina, and S. guttatus) for the isolation of V. cholerae bacteria, where culturing as well biochemical tests were performed for the identification and characterization of isolates, molecular study through partial $16 \mathrm{~S}$ ribosomal RNA gene amplification was done after DNA isolation and quality checking.

All four marine fishes selected showed the presence of $V$. cholerae. This show that the incidence of $V$. cholerae bacteria isolated is significant in marine fishes. The selective media TCBS agar showed the presence of the $V$. cholerae bacteria yellow colonies is observed on TCBS agar plates after $24 \mathrm{hrs}$ of incubation. The isolates were presumptively identified by biochemical profiling the different reactions and different changes in the media due to the behavior of isolated bacteria to the subjected media and chemicals present in media different changes were observed and compared to the standards records all the four isolates were positive for tests performed except Gram staining which characterized the isolates as Gram-negative (Table 1), the amplification of 16s rRNA gene is another factor which confirms that the isolates are bacteria there is confirmation of $V$. cholerae (Table 2). Genomic DNA was isolated and characterized by standard proteinase-K digestion method, and its quality was checked using agarose gel methods, PCR was performed using universal primers $27 \mathrm{~F}$ and 1492R the products were observed as 1500 bp (Fig. 1). Antibiotic sensitivity tests were carried on MHA plates by Kirby-Bauer disk diffusion method using HiMedia ready to use antibiotic discs showed a different zone of inhibition (Table 2). Characterization of the isolates as susceptible, intermediately resistant, or resistant was based on the size of inhibition zones around each disc as per the manufacturer's instructions, which matched the interpretive criteria as per CLSI guidelines (Table 2) (CLSI, 2007) [8].

\section{DISCUSSION}

Food contamination continues to be a worldwide problem. Recent development in food production and processing techniques and the subsequent changing trends in food consumption have resulted in the emergence of new hazards. Consumption of untreated water and uncooked seafood in summer is another epidemiologic evidence of $V$. cholerae transmission [8]. Therefore; this study was conducted to isolate, to identify and antibiotic susceptibility evaluation of $V$. cholerae in different fish species. $V$. cholerae the causative agent of cholera was first described by Robert Koch in 1883. Vibrio organisms are free living widely distributed highly motile Gram-negative curved or commashaped rods with a single polar flagellum, and most species are oxidase positive [9]. $V$. cholerae is spread by eating food or drinking water that has been contaminated with cholera bacteria. Contamination usually occurs when human feces from a person who has the disease seeps into a community water supply [10]. In different studies, the incidence of $V$. cholerae sample collection was done from different localities to give a good chance for isolation of different bacteria and for determination greater incidence in different food materials, in our study the sample collection was done in local market targeting different

Table 1: Biochemical tests performed

\begin{tabular}{lllll}
\hline Tests & S1 & S2 & S3 & S4 \\
\hline Gram staining & - & - & - & - \\
Oxidase & + & + & + & + \\
Catalase & + & + & + & + \\
Citrate utilization & + & + & + & + \\
Nitrate reduction & + & + & + & + \\
Indole test & + & + & + & + \\
Methyl red & + & + & + & + \\
\hline
\end{tabular}

Table 2: Antibiotics susceptibility profile of isolates

\begin{tabular}{|c|c|c|c|c|c|c|c|c|}
\hline \multirow[t]{2}{*}{ Antibiotics } & \multicolumn{4}{|c|}{$\begin{array}{l}\text { Zone of } \\
\text { inhibition }(\mathrm{mm})\end{array}$} & \multicolumn{4}{|c|}{$\begin{array}{l}\text { Interpretive chart } \\
\text { according to NCCLS }\end{array}$} \\
\hline & S1 & S2 & S3 & S4 & S1 & S2 & S3 & S4 \\
\hline Penicillin G & 17 & 15 & 13 & 18 & S & $\mathrm{S}$ & S & $\mathrm{S}$ \\
\hline Streptomycin & 17 & 18 & 18 & 15 & S & $\mathrm{S}$ & I & I \\
\hline Chloramphenicol & 25 & 15 & 25 & 23 & S & I & $\mathrm{S}$ & S \\
\hline Ampicillin & 35 & 32 & 30 & 33 & $\mathrm{~S}$ & $\mathrm{~S}$ & $\mathrm{~S}$ & S \\
\hline Amoxicillin & 0 & 0 & 0 & 0 & $\mathrm{R}$ & $\mathrm{R}$ & $\mathrm{R}$ & $\mathrm{R}$ \\
\hline Tetracycline & 30 & 25 & 25 & 27 & $\mathrm{~S}$ & $\mathrm{~S}$ & $\mathrm{~S}$ & S \\
\hline Ciprofloxacin & 24 & 24 & 25 & 25 & $\mathrm{~S}$ & $\mathrm{~S}$ & $\mathrm{~S}$ & S \\
\hline Co-trimoxazole & 25 & 26 & 30 & 27 & S & $\mathrm{S}$ & $\mathrm{S}$ & S \\
\hline Nitrofurantoin & 6 & 7 & 0 & 0 & $\mathrm{R}$ & $\mathrm{R}$ & $\mathrm{R}$ & $\mathrm{R}$ \\
\hline Norfloxacin & 27 & 28 & 25 & 23 & $\mathrm{~S}$ & $\mathrm{~S}$ & S & S \\
\hline
\end{tabular}

S1, 2, 3, 4: Isolate one, two, three, and four, S: Susceptible, I: Intermediate,

R: Resistance 


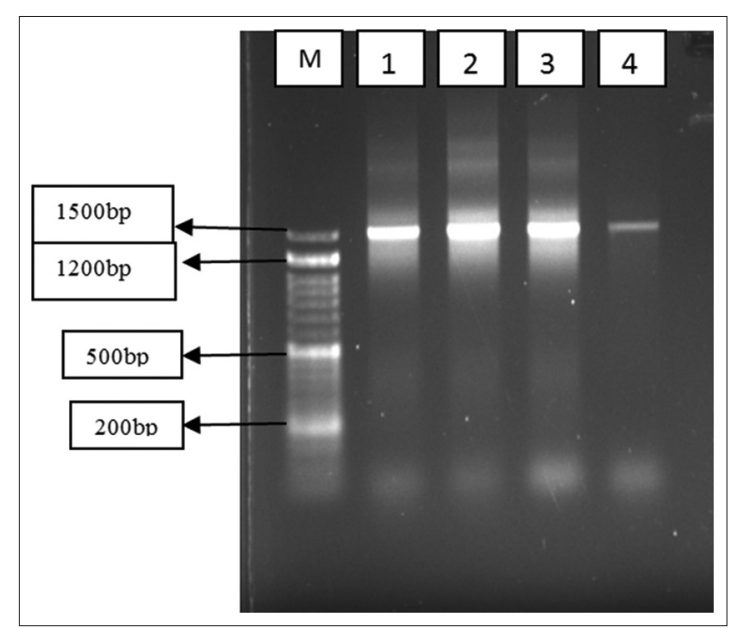

Fig. 1: Agarose gel electrophoresis of polymerase chain reaction products amplified with $16 \mathrm{~S}$ rRNA primer from the genomic DNA of Vibrio cholerae isolates

marine fish species available, in this study the selected fish species show the presence of targeted bacteria this show the contamination of water also, here the prevalence of $V$. cholerae is high. Biochemical tests performed revealed phenotypic similarities of the two species observed in the results of oxidase, TSI, catalase, and methyl red Voges-Proskauer tests [11] asserts that the tests which have been applied in this study were able to efficiently differentiate these species. Thus, for detection of the species of the isolates, the conventional biochemical tests showed the low efficiency. Molecular identification becomes a great tool in the area of clinical diagnosis; PCR-based detection targets the specific region of DNA, for identification of bacterial strains. Furthermore, PCR facilitates the identification of the strains that are viable but non-culturable [12] in this study $16 \mathrm{~S}$ rRNA gene was amplified and showed great results. It is less labor intensive and much faster than conventional methods, and that is the reason of its increasing application among investigators [13]. The antibiogram profile revealed that isolates, all isolates showed multi-drug resistant to amoxicillin and nitrofurantoin. And they are susceptible to the remaining antibiotics used in this study which is commonly used to treat cholera infection. Mukhopadhyay et al. [14] reported the ineffectiveness of co-trimoxazole and furazolidone to treat patients with $V$. cholerae 01 infection and appearance of nalidixic acid resistance among 01 strains from Calcutta patients [15], isolated and reported tetracycline resistant strains in Kolkata in the year 2005. There is an agreement between the results that show high individual and multiple antibiotics resistance among all examined Vibrio strains, and other researchers [16,17]. Antibiotics provide the main basis for the therapy of microbial infections. However, the high genetic variability of microorganisms enables them to rapidly evade the action of antibiotics by developing antibiotic resistance [18]. One study revealed that all Vibrio strains were found to harbor antibiotics resistant genes and showed resistances to ampicillin, furazolidone, nalidixic acid, streptomycin, trimethoprim-sulfamethoxazole, and trimethoprim [19]. Thungapathra et al. indicated that in a total number of 94 isolates of V. cholera, 43 strains contained R-plasmids and exhibited resistances to ampicillin, neomycin, tetracycline, gentamicin, streptomycin, sulfonamide, furazolidone, and chloramphenicol [20]. The isolates are not much resistant consider to the other well-reported cases of Vibrio outbreaks. Hence, there is an urgent need for the discovery of new and novel antimicrobial drugs to effectively eradicate the diseases producing microorganisms [21].

\section{CONCLUSION}

This is the study that describes the occurrence, molecular characterization and antibiotic susceptibility pattern of $V$. cholerae isolated in marine fish species. Molecular methods could be rapid and concise methods for the detection of foodborne bacteria. This study revealed the development of multidrug resistance among Vibrio strains in this region. High measures need a continuous vigilance on the changing trend in the antibiotic susceptibility pattern of $V$. cholerae which is due to environmental factors and widespread use of antibiotics. Finally, the results of this study indicated possible risks to consumers of marine fishes in the region that demand action to address this public health concern.

\section{REFERENCES}

1. Seas C, Alarcon M, Aragon JC, Beneit S, Quiñonez M, Guerra H, et al. Surveillance of bacterial pathogens associated with acute diarrhea in Lima, Peru. Int J Infect Dis 2000;4(2):96-9.

2. Sharma NC, Mandal PK, Dhillon R, Jain M. Changing profile of Vibrio cholerae O1, O139 in Delhi and its periphery (2003-2005). Indian J Med Res 2007;125(5):633-40.

3. Torane V, Kuyare S, Nataraj G, Mehta P, Dutta S, Sarkar B. Phenotypic and antibiogram pattern of $V$. cholerae isolates from a tertiary care hospital in Mumbai during 2004-2013: A retrospective cross-sectional study. BMJ Open 2016;6(11):e012638.

4. Raytekar NA, Saini S, Bhalerao D, Deorukhkar S, LSarkar B. A bacteriological study of Vibrio cholerae isolated from rural tertiary care hospital of Loni, Western Maharashtra. Br Microbiol Res J 2014;4(9):949.

5. Morris JG Jr, Sztein MB, Rice EW, Nataro JP, Losonsky GA, Panigrahi $\mathrm{P}$, et al. Vibrio cholerae $\mathrm{O} 1$ can assume a chlorineresistant rugose survival form that is virulent for humans. J Infect Dis 1996;174(6):1364-8.

6. Jones RN, Sader HS, Fritsche TR, Janechek MJ. Selection of a surrogate $\beta$-lactam testing agent for initial susceptibility testing of doripenem, a new carbapenem. Diagn Microbiol Infect Dis 2007;59(4):467-72.

7. Bauer AW, Kirby WM, Sherris JC, Turck M. Antibiotic susceptibility testing by a standardized single disk method. Am J Clin Pathol 1966;45(4):493-6.

8. Gilmour MW, Martel-Laferriere V, Lévesque S, Gaudreau C, Bekal S, Nadon C, et al. Vibrio cholerae in traveler from Haiti to Canada. Emerg Infect Dis 2011;17(6):1124-5.

9. Lee JH, Rho JB, Park KJ, Kim CB, Han YS, Choi SH, et al. Role of flagellum and motility in pathogenesis of Vibrio vulnificus. Infect Immun 2004;72(8):4905-10.

10. Schild S, Lamprecht AK, Reidl J. Molecular and functional characterization of $\mathrm{O}$ antigen transfer in Vibrio cholerae. J Biol Chem 2005;280(27):25936-47.

11. Kaysner CA, DePaola A Jr. Vibrio cholerae, V. parahaemolyticus, $V$. vulnificus, and other Vibrio sp. US Food and Drug Administration Bacteriological Analytical Manual Online. Washington, DC: US Food and Drug Administration; 2003.

12. Binsztein N, Costagliola MC, Pichel M, Jurquiza V, Ramírez FC, Akselman R, et al. Viable but nonculturable Vibrio cholerae O1 in the aquatic environment of Argentina. Appl Environ Microbiol 2004;70(12):7481-6.

13. Teh CS, Chua KH, Thong KL. Simultaneous differential detection of human pathogenic and nonpathogenic Vibrio species using a multiplex PCR based on gyrB and pntA genes. J Appl Microbiol 2010;108(6):1940-5.

14. Mukhopadhyay AK, Garg S, Nair GB, Kar S, Ghosh RK, Pajni S, et al. Biotype traits and antibiotic susceptibility of Vibrio cholerae serogroup O1 before, during and after the emergence of the O139 serogroup. Epidemiol Infect 1995;115(3):427-34.

15. Roychowdhury A, Pan A, Dutta D, Mukhopadhyay AK, Ramamurthy T, Nandy RK, et al. Emergence of tetracycline-resistant Vibrio cholerae O1 serotype Inaba, in Kolkata, India. Jpn J Infect Dis 2008;61(2):128-9.

16. Ansari M, Raissy M. In vitro susceptibility of commonly used antibiotics against Vibrio sp. isolated from lobster (Panulirus homarus). Afr J Microbiol Res 2010;4(23):2629-31.

17. Okoh AI, Igbinosa EO. Antibiotic susceptibility profiles of some Vibrio strains isolated from wastewater final effluents in a rural community of the Eastern Cape province of South Africa. BMC Microbiol 2010;10(1):143.

18. Leelaprakash G, Dass SM. Antimicrobial activity and phytochemical screening of methanol extract of Enicostemma axillare. Int J Pharm Pharm Sci 2012;4(1):342-8.

19. Ramachandran D, Bhanumathi R, Singh DV. Multiplex PCR for detection of antibiotic resistance genes and the SXT element: Application in the characterization of Vibrio cholerae. J Med Microbiol 
2007;56(3):346-51.

20. Thungapathra M, Sinha KK, Chaudhuri SR, Garg P, Ramamurthy T, Nair GB, et al. Occurrence of antibiotic resistance gene cassettes aac $\left(6^{\prime}\right)-\mathrm{Ib}$, dfrA5, dfrA12, and ereA2 in class I integrons in non-O1, non-O139 Vibrio cholerae strains in India. Antimicrob Agents
Chemother 2002;46(9):2948-55

21. Suresh M, Arularasan S, Srikumaran N. Screening on antimicrobial activity of marine gastropods Babylonia zeylanica (Bruguière, 1789) and Harpa conoidalis (Lamarck, 1822) from Mudasalodai, Southeast coast of India. Int J Pharm Pharm Sci 2012;4(4):552-6. 